\title{
Development of a Switched Reluctance Motor-based Electric AC Compressor Drive for HEV/EV Applications
}

\author{
Jaehyuck Kim $^{1 *}$, Yong-hoe Jeong ${ }^{1}$, Yong-Hee Jeon ${ }^{1}$, Jun-Ho Kang ${ }^{1}$, Seunghun Lee ${ }^{2}$, and Jang-Yeop Park ${ }^{3}$ \\ ${ }^{1}$ Dept. of Electrical Engineering, Wonkwang University, Iksan 570-749, Korea \\ ${ }^{2}$ Kaya Climate Control Corp., Gimhae 621-844, Korea \\ ${ }^{3}$ LC TEK, Gumi 730-032, Korea
}

(Received 7 March 2014, Received in final form 4 July 2014, Accepted 8 July 2014)

\begin{abstract}
This paper discusses the development of a $3.5 \mathrm{~kW}$ switched reluctance motor (SRM)-based electric air-conditioning (AC) compressor, focusing primarily on the design aspects of the SRM and the integrated controller. In addition to the increased price of rare-earth magnets, SRM's operation capability at high speed and high temperature makes the SRM a viable alternative to the permanent magnet motor for electrically driven automotive air conditioning compressors. A compact and energy efficient scroll compressor is designed and constructed. Two feasible SRM topologies are considered, in terms of efficiency, torque ripple, and acoustic noise. Compact drive electronics are designed and employed to drive the SRM-based compressor. The static and dynamic performance is validated by simulation and experiment.
\end{abstract}

Keywords : switched reluctance motor, electric AC compressor

\section{Introduction}

The exhaustion of fossil fuels, rising oil prices, and car exhaust pollution have been ever-growing interrelated concerns, resulting in extensive research and development of environmentally friendly vehicles to replace conventional internal combustion engine (ICE) vehicles. In particular, the growing prevalence of electric vehicles (EV) and hybrid electric vehicles (HEV) has even intensified the deployment of automotive motor drives for critical applications, including HVAC (heating, ventilating, and air-conditioning), engine management systems, automotive transmissions, ABS, electric parking systems, and integrated starter/generators.

While electric powertrains and energy storage systems affect driving performance, many of the accessory drive systems provide important functions related to safety and comfort. One of the important accessory systems in EVs/ HEVs is the electric air-conditioning (AC) system. In electric AC systems, a compressor is driven by an integrated electric motor, unlike the belt-driven internal combustion engine vehicles. The electric AC system is able to

CThe Korean Magnetics Society. All rights reserved.

*Corresponding author: Tel: +82-63-850-6733

Fax: +82-63-850-6745, e-mail: jaehkim@wku.ac.kr control the cooling capacity irrespective of the number of revolutions of the engine, and even in the idling state that requires the greatest cooling capacity, hence providing a comfortable environment $[1,2]$.

For electric AC systems in EVs/HEVs, a smaller, lighter, and more efficient air-conditioning compressor is required, and the motor sin electric compressors should be capable of high torque and high efficiency, with compact volume [3]. In the case of high performance electric compressors, permanent magnet motors (PMSM or BLDC type) are mainly employed. Recently, however, non-rare earth motors are often considered, due to the rise of rare earth permanent magnet prices.

The switched reluctance motor (SRM) is one of the typical non-rare earth magnet motors that has received great attention in automotive applications. The SRM does not require permanent magnets, and has the advantages of low manufacturing cost and reliability. The SRM is known to be the lowest cost motor with the simplest construction, having no brushes, commutators, windings, or magnets on its rotor, and only concentrated windings on its stator [4]. Converters for SRMs can be made simple, in comparison to the complex inverter for ac motors. Significant research has been under taken to extend the feasibility of SRM drive technologies. However, acoustic noise and torque ripple are the major drawbacks obstructing the 
widespread application of SRM technologies.

This paper presents the development of a $3.5 \mathrm{~kW}$ SRMbased electric compressor system that targets commercial EVs/HEVs. A compact scroll compressor and a non-rare earth SRM with an integrated converter are designed and constructed. The design, construction, and experimental verification of a prototype compressor drive are discussed in the following sections, to validate the feasibility of the proposed electric drive system.

\section{The Electrical Air-Conditioning System}

In comparison with domestic or commercial applications, the automotive application places very special demands on the air-conditioning (AC) system. Particularly demanding requirements of the compressors specific to automotive applications are not only the higher duty-per-unit volume, but also the stringent constraints on size, weight, cost, efficiency, low acoustic noise, and vibration [3]. As a result of these constraints deriving from the use of an

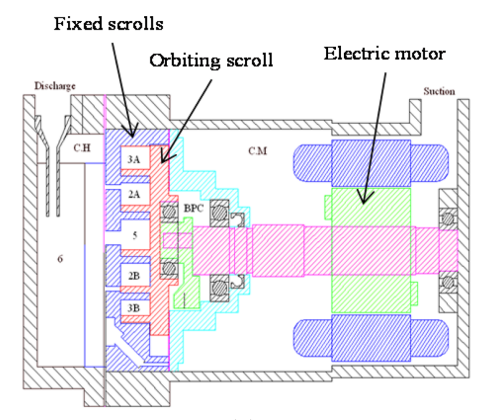

(a)

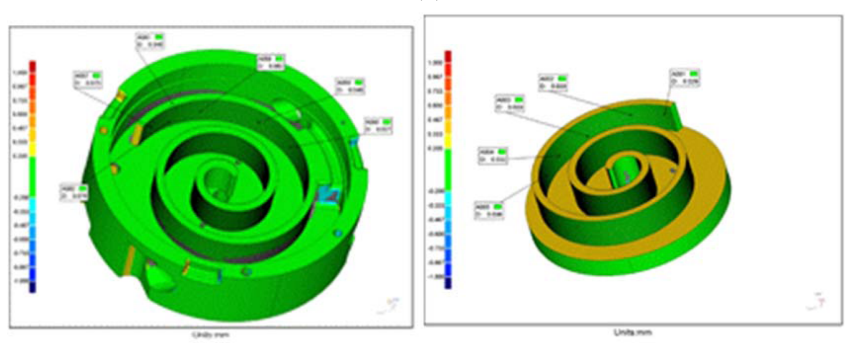

(b)

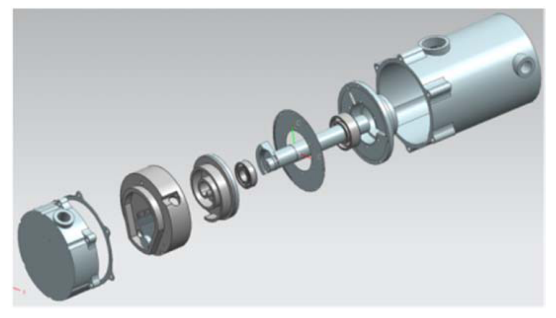

(c)

Fig. 1. (Color online) Electric motor driven scroll compressor: (a) Cross-sectional drawing of thescroll compressor. (b) The two interleaving scrolls (fixed and orbiting), and (c) 3D modeling of the construction of the scroll compressor. engine driven compressor, the electrical AC system provides several advantages to the $\mathrm{EV}$ performance. The desired electric AC system should employ an integrated system of air compressor, electric motor, and drive electronics.

\subsection{Scroll Compressor}

While the traditional swash plate or rotary vane compressor is widely used in automotive applications, the scroll compressor provides high EER (energy and efficiency ratio), and excellent reliability [3], due to its compactness and higher cooling capacity. Therefore, a compact scroll compressor with a similar volume, as well as the equivalent refrigeration capacity, is the desirable option for small vehicle applications. Fig. 1 shows acrosssectional view of the scroll compressor, which is composed of an electric motor, and two interleaving scrolls to pump, compress, or pressurize fluids. The scroll compressor is very efficient and quiet, but represent a challenge for manufacture, and hence for cost. Fig. 1(c) shows 3D modeling of the scroll compressor employed in this paper.

Equations to describe the dynamic behavior of the scroll compressor are derived for design procedure and analytic verification. Forces acting on the orbiting scroll, considering radial forces, tangential forces, and axial moments, are depicted in Fig. 2, and their equations are given by:

$$
\begin{aligned}
\left(\begin{array}{c}
\sum F_{t}=0 \\
\sum F_{r}=0 \\
\sum M_{t}=0 \\
\sum M_{r}=0
\end{array}\right) & \left(\begin{array}{cccc}
1 & 0 & 0 & 0 \\
0 & 0 & 0 & -1 \\
0 & F_{d} & 0 & \frac{b}{2} \\
l_{h u b} & 0 & -F_{d} & 0
\end{array}\right)\left(\begin{array}{c}
F_{c p t} \\
r_{x} \\
r_{y} \\
F_{o r r}
\end{array}\right) \\
& =\left(\begin{array}{c}
F_{t g}+\mu_{t} F_{d} \\
F_{r g}-F_{o s c} \\
-F_{r g}\left(\delta+\frac{h}{2}\right)-F_{a}\left(\frac{r_{s}}{2}\right)+F_{o s c} l_{c} \\
-F_{t g}\left(\delta+\frac{h}{2}\right)+\delta \mu_{t} F_{d}
\end{array}\right)
\end{aligned}
$$

where, $F_{t}$ is the tangential force, $F_{r}$ is the radial force, $M_{t}$ is the tangential moment, and $M_{r}$ is the radial moment.

\subsection{Motor Configuration}

Table 1 shows the specifications of a three-phase SRM to drive the scroll compressor. While the two-phase SRM is often considered in household or low-cost volume applications, where size and cost are of prime concern, the three-phase SRM is better suited for compressor applications, due to its lesser torque ripple and lesser semi- 


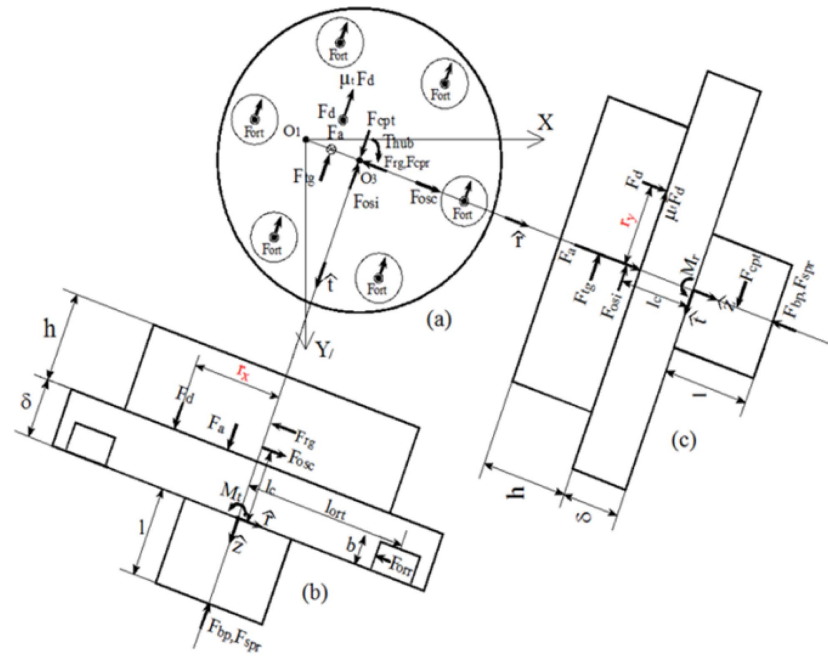

Fig. 2. (Color online) Forces and moments acting on the orbiting scroll.

Table 1. Motor Operating Specifications

\begin{tabular}{ccc}
\hline \hline Specification & Value & Unit \\
\hline Nominal voltage & 288 & $\mathrm{~V}$ \\
Rated output power & 3.5 & $\mathrm{~kW}$ \\
Rated Voltage & 288 & $\mathrm{~V}$ \\
Rated Speed & 7500 & $\mathrm{RPM}$ \\
Rated Torque & 3.9 & $\mathrm{~N}-\mathrm{m}$ \\
\hline
\end{tabular}

conductor VA rating. Several types of stator/rotor configurations were initially considered, but $6 / 4$ and $12 / 8$ were selected in this paper. Fig. 3 shows the geometrical dimensions for the prototype 6/4 SRM. (The dimensions for the $12 / 6 \mathrm{SRM}$ are defined similarly.) $D_{s}$ is the stator outer diameter. $D_{r}$ is the rotor outer diameter, $D_{s h}$ is the rotor shaft diameter, $y_{s}$ is the stator yoke thickness, $y_{r}$ is the rotor yoke thickness, $P W_{s}$ is the stator pole thick thickness, $P W_{r}$ is the rotor pole thick thickness, $\beta_{s}$ is the stator pole arc, $\beta_{r}$ is the rotor pole arc, and $g$ is the air gap

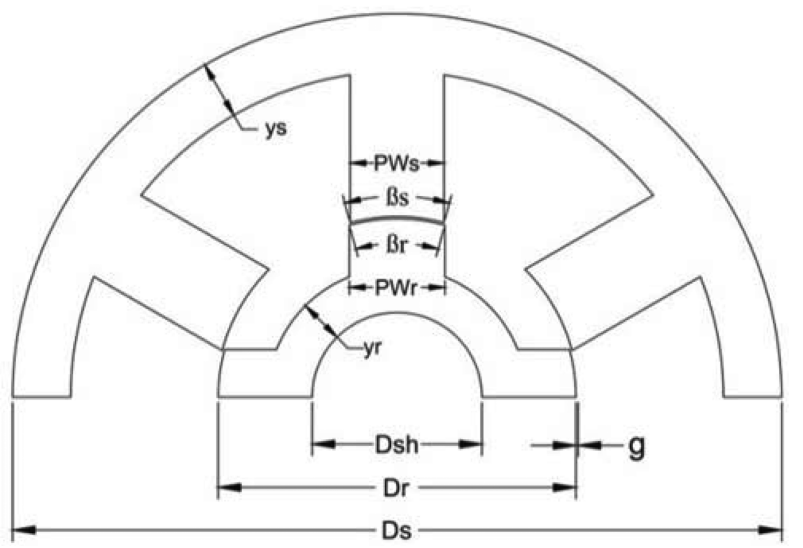

Fig. 3. Geometrical parameters of the 6/4 SRM. length.

The key design parameters are derived as follows. The stator dimensions are determined such that the acoustic noise, vibration, and ovalization are minimized. To this end, the stator pole width, $P W_{s}$ is given by:

$$
P W_{s}=2 \times\left(\frac{D_{s}}{2}+g\right) \times \sin \left(\frac{\beta_{s}}{2}\right)
$$

The stator yoke thickness is given by:

$$
y_{s}=P W_{s} \times \frac{2}{3}
$$

The rotor pole width, $P W_{r}$ is given by:

$$
P W_{r}=D_{r} \times \sin \left(\frac{\beta_{s}}{2}\right) \times \frac{2}{3}
$$

The rotor yoke thickness is given by:

$$
y_{r}=P W_{r} \times \frac{2}{3}
$$

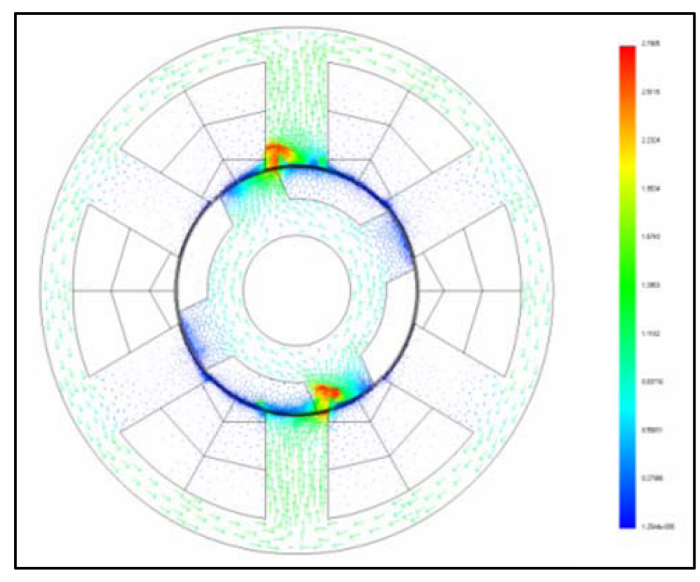

(a)

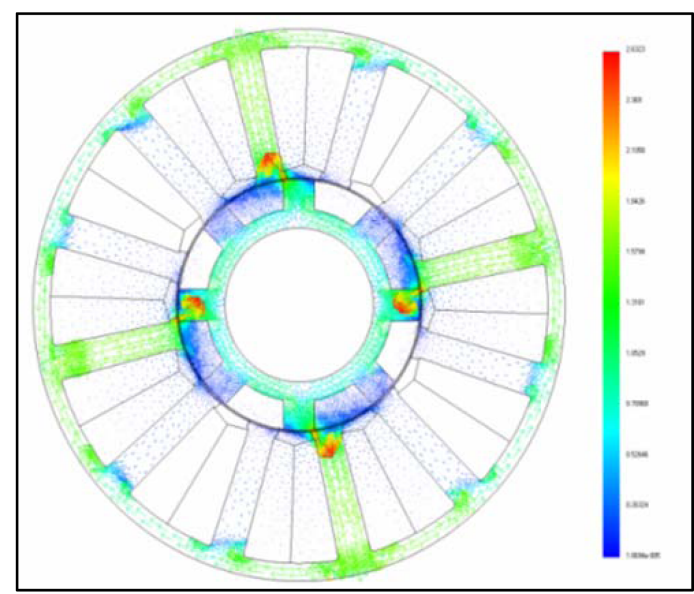

(b)

Fig. 4. (Color online) Flux density plots of (a) 6/4SRM, and (b) 12/8 SRM, from FEA simulation. 
Table 2. Comparison of the three motors

\begin{tabular}{cccc}
\hline \hline Specification & $6 / 4$ & $12 / 8$ & Unit \\
\hline No. of phases & 3 & 3 & - \\
No. of stator/rotor poles & $6 / 4$ & $12 / 8$ & - \\
Output Power & 3.55 & 3.69 & $\mathrm{~kW}$ \\
Core Loss & 195.5 & 370.8 & $\mathrm{~W}$ \\
Copper Loss & 455.89 & 319.53 & $\mathrm{~W}$ \\
Efficiency & 82.2 & 81.1 & $\%$ \\
Torque ripple & 43.9 & 41.4 & $\%$ \\
\hline
\end{tabular}

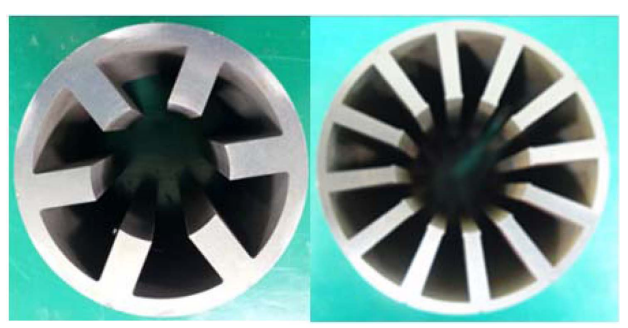

(a)

(b)

Fig. 5. (Color online) Construction of stators (a) 6/4, and (b) $12 / 8$.

To verify the static performance, and obtain the magnetic and torque characteristics of the SRMs, finite element analysis (FEA) was conducted. Fig. 4 shows plots of the flux densities of both motors. Table 2 provides a comparative summary of the two prototype SRMs.

While the $12 / 8$ topology has less torque ripple than the $6 / 4$, the $6 / 4$ topology is found to be slightly better in efficiency specifically at high speed, due to the lesser commutation frequency, compared to that of $12 / 8$. Fig. 5 shows the constructed stators of the two prototype motors (6/4 and 12/8).

\subsection{Motor Controller}

The key issues of the integration of electronics with compressor include compact packaging, thermal management, and EMI. Integrating the motor drive is of prime importance, due to the harsh environment that the motor and drive electronic components would be exposed to inside the compressor housing. Two types of mounting methods of the controllers are considered, as shown in Fig. 6: (a) internal mounting inside the motor housing, or (b) external mounting outside the motor housing. While internal mounting would be most effective for packaging, external mounting can provide the controller electronics with better protection to the refrigerant and lubricating compound.

Fig. 7 shows the PCBs construction for power stages, gate drivers, signal interface, embedded controller, etc.).

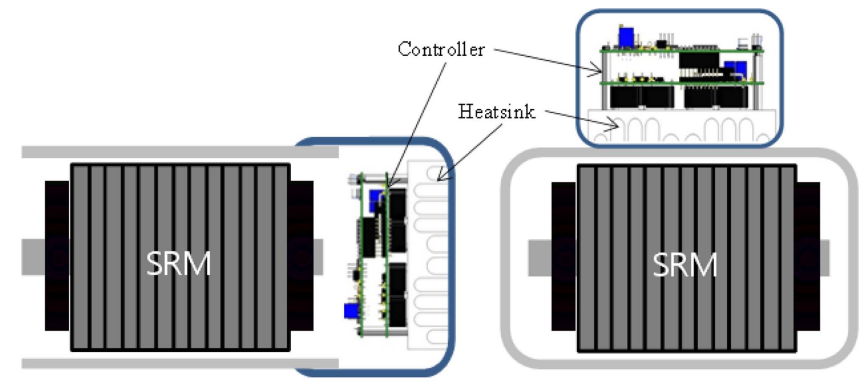

(a)

(b)

Fig. 6. (Color online) Integration of motor controller. (a) configuration of internally mounted controller, and (b) externally mounted controller.

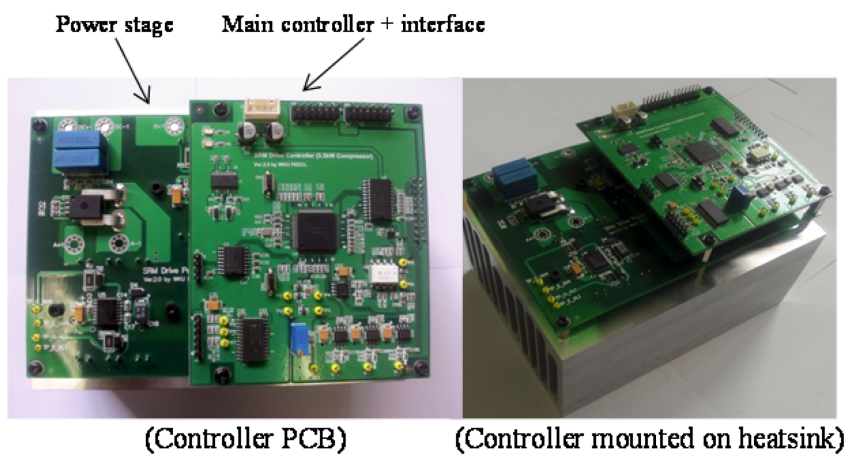

Fig. 7. (Color online) Construction Integration of motor controller. (a) configuration of internally mounted controller, and (b) externally mounted controller.

The motor is mounted directly onto the compressor housing, with an additional heat sink. The compressor housing is also used as a heat sink plate, due to the natural cooling action of the internal refrigerant flow.

\section{Dynamic Simulation and Drive Control}

\subsection{Derivation of System Equations}

System equations to model the operation of the SRM combined with the converter are derived in this section. The flux, $\lambda$ linking the phase coil is a function of the rotor position, $\theta$ and the phase current, $i$. Without rotor coils, an SRM has no rotor field excitation. Phase coupling is usually low in SRDs, and occurs only when currents simultaneously conduct in more than one phase. For this reason, mutual inductance is neglected. Therefore, the phase flux is a function of the rotor angle and phase current:

$$
\frac{d \lambda(\theta, i)}{d t}=v-R i
$$

Since the flux is the product of the current and induc- 
tance, $\lambda=L i$, the product rule can be applied to the derivative on the left side of Eq. (6):

$$
i \frac{d L}{d t}+L \frac{d i}{\partial t}=v-R i
$$

Applying the chain rule for derivatives of multivariable equations to Eqs. (6) and (7), respectively, gives

$$
\begin{aligned}
& \frac{\partial \lambda}{\partial \theta} \omega+\frac{\partial \lambda}{\partial i} \frac{\partial i}{\partial t}=v-R i \\
& i\left(\frac{\partial L}{\partial \theta} \omega+\frac{\partial L}{\partial i} \frac{\partial i}{\partial t}\right)+L \frac{d i}{d t}=v-R i
\end{aligned}
$$

where, $\omega=\partial L / \partial t$ is the rotor angular velocity in $\mathrm{rad} / \mathrm{sec}$. The first term in (9) is referred to as the back EMF, and is the product of the partial inductance derivative, with respect to the rotor position and rotor speed. The second term in (9) contributes the effects of inductance saturation, and is zero in the absence of saturation. The third term is the inductive voltage drop.

The mechanical dynamics for motors relates the air gap torque, $T_{e}$ to angular motion:

$$
\frac{d \omega}{d t}=T_{e}(\theta, i)-B \omega-T_{l}
$$

where, $J$ is the rotor angular inertia, $B$ is the viscous friction constant, and $T_{L}$ is the load torque. The air gap torque is the sum of the torque generated by each phase, and is a function of the current and rotor angle. In the absence of magnetic phase saturation, the phase torque is equal to the product of the inductance derivative with respect to angle, and the phase current squared:

$$
T_{e}(\theta, i)=\frac{1}{2} i^{2} \frac{\partial L(\theta, i)}{\partial \theta}
$$

\subsection{Controller Design}

Fig. 8 shows a block diagram of the current control loop for one SRM phase with a linear PI controller. The transfer function of the PI current controller and the openloop gain of the current control loop are given by Eqs. (12) and (13), respectively:

$$
\begin{aligned}
G_{c}(s) & =\frac{K_{c}\left(1+s T_{c}\right)}{s T_{c}} \\
G_{c}^{0}(s) & =\frac{K_{c}\left(1+s T_{c}\right)}{s T_{c}} \cdot K_{r} \cdot \frac{1}{R+s L}
\end{aligned}
$$

where, $K_{r}$ is the converter gain.

Fig. 9 shows a block diagram of the speed control loop with a linear PI controller.

The transfer function of the PI speed controller and the

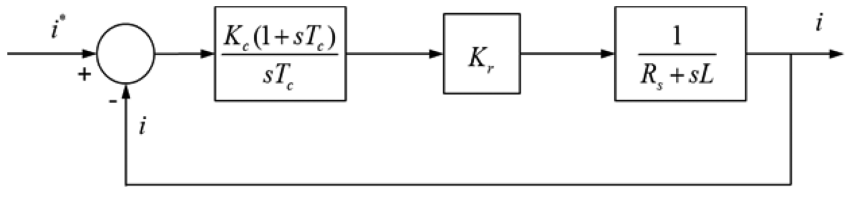

Fig. 8. Block diagram of current control loop.

open-loop gain of the speed control loop are given by Eqs. (14) and (15), respectively:

$$
\begin{aligned}
G_{s}(s) & =\frac{K_{s}\left(1+s T_{s}\right)}{s T_{s}} \\
G_{s}^{0}(s) & =\frac{K_{s}\left(1+s T_{s}\right)}{s T_{s}} \cdot K_{T} \cdot \frac{1}{B+J_{s}}
\end{aligned}
$$

where, $K_{T}$ is the torque constant. In order to obtain correct simulation results, knowing the accurate values of $J$ and $B$ is crucial.

Fig. 8 shows a block diagram of the variable speed SRM control, including a closed-loop speed controller, current controller, and on-line angle controller. A Linear PI controller with anti-windup is employed. Turn-on and turn-off angles are determined, considering the system efficiency, torque ripple, and torque production beyond the base speed.

Using the derived Eqs. (6), (9) and (10), a simulation model of a $3.5 \mathrm{~kW}$ three-phase SRM, including a power converter to drive the scroll compressor, was developed, as shown in Fig. 10, which shows the overall SRM drive system, three-phase SRM magnetic and electromechanical characteristics derived from the 2D FEA results, and the closed-loop speed controller with anti-windup.

Using the Simulink model derived above, simulation was carried out, and the results for the static and dynamic performance of the SRM drive are plotted in Fig. 11 and Fig. 12, respectively. Fig. 11 shows the three phase currents (phase a, phase b, phase c) and electromagnetic torque, when the motor is running at the rated speed of $7500 \mathrm{rpm}$, and producing $3.9 \mathrm{~N}-\mathrm{m}$. Fig. 12 shows the dynamic performance of the speed controlled SRM drive running from standstill to $5000 \mathrm{rpm}$. It can be seen that closedloop controller works very well, in the presence of load disturbance at $0.01 \mathrm{~s}$.

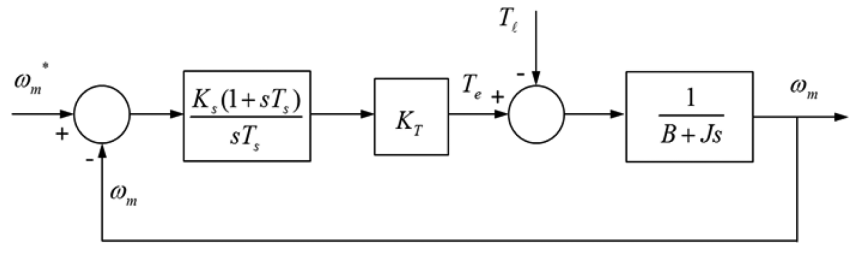

Fig. 9. Block diagram of speed control loop. 


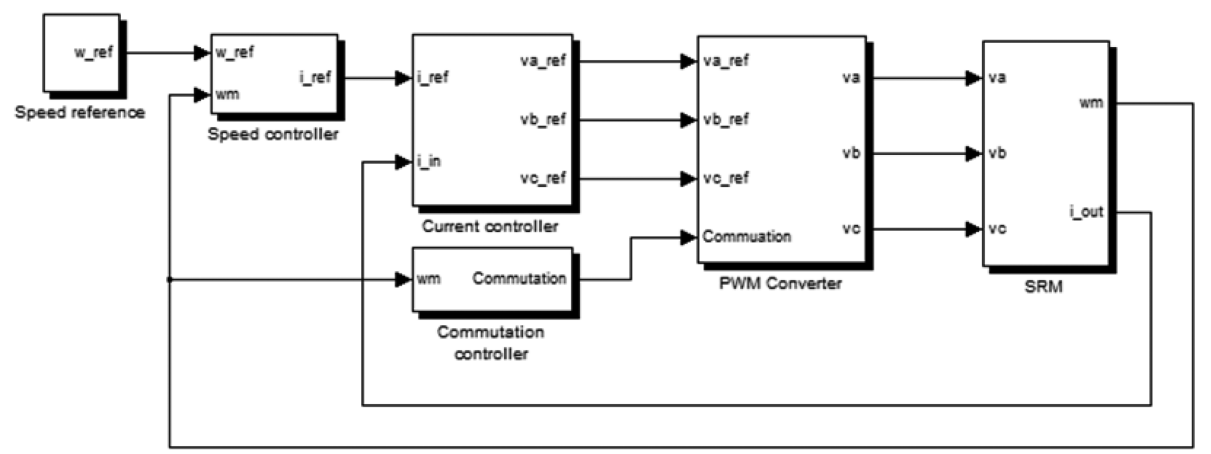

(a)

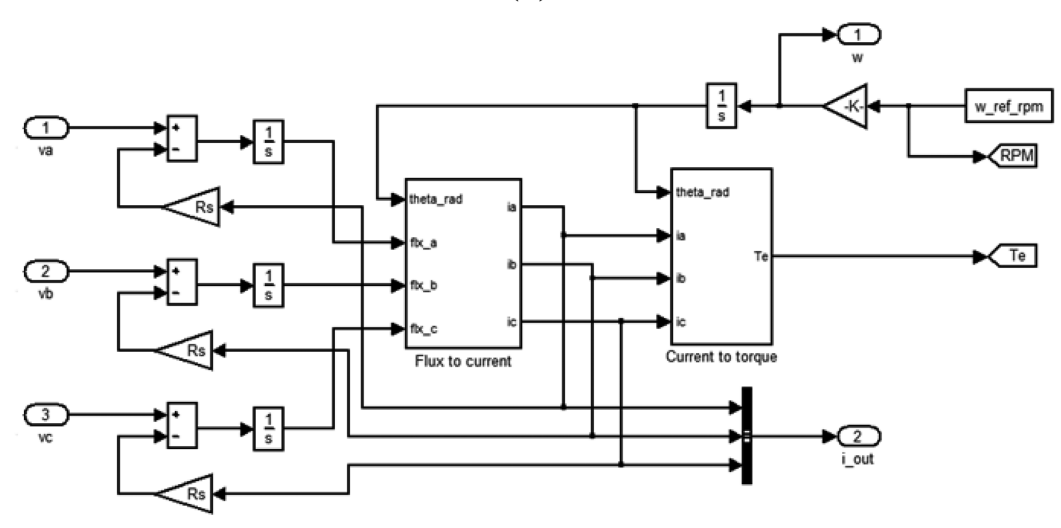

(b)

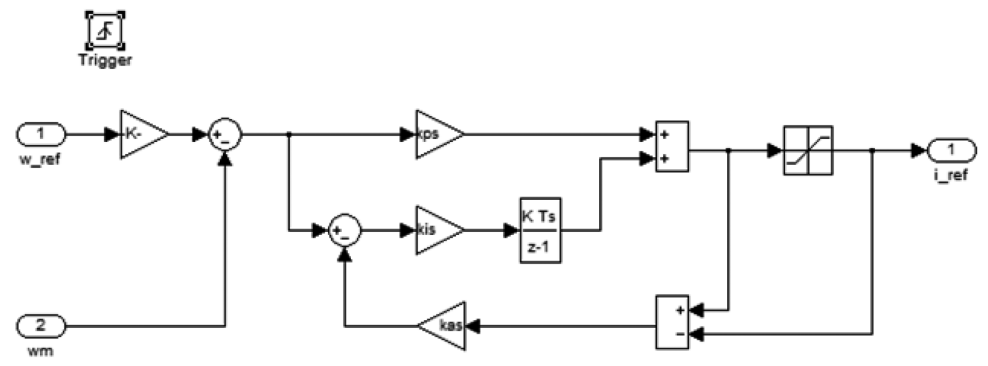

(c)

Fig. 10. Simulink block diagram of the $3.5 \mathrm{~kW}$ SRM drive (a) overall drive system, (b) three-phase SRM, and (b) Speed-controller with anti-windup.

\subsection{Sensorless Position Estimation}

To minimize the number of hermetic connections and achieve further cost reduction, sensorless control should be employed, and this should be the key to success of the SRM drive in AC compressor applications. In this paper, the conventional flux estimation-based sensorless control algorithm [11, 12], combined with the current-gradient method [13] as a fault-tolerant backup at high speed, was implemented.

Fig. 13 shows an algorithm to determine the turn-off position, by improving the drawbacks of the conventional flux-estimation method.
The rotor angular speed can be calculated using the time interval between two adjacent turn-off angles of one phase, as depicted in Fig. 14:

$$
\begin{aligned}
& \Delta \theta=\frac{2 \pi}{m \cdot N_{r}}[\mathrm{rad}] \\
& \omega=\frac{2 \pi}{m \cdot N_{r}} \cdot \frac{1}{\Delta T}[\mathrm{rad} / \mathrm{s}]
\end{aligned}
$$

$\Delta \theta$ and $\Delta T$ are the angular and time intervals between the two adjacent turn-off angles, respectively, and $m$ is the number of motor phases.

Considering the advance in turn-on angle, the turn-on 

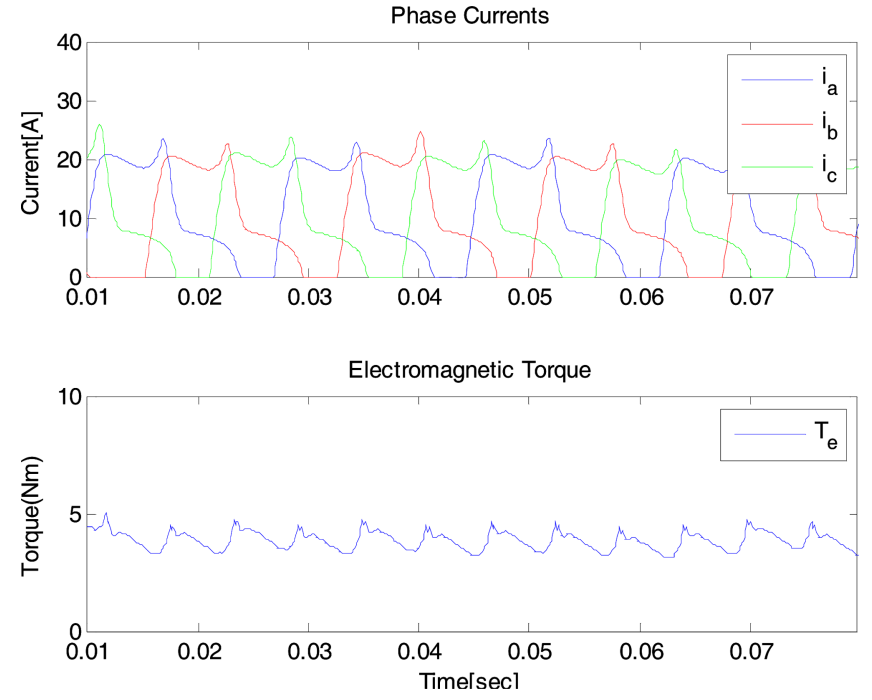

Fig. 11. (Color online) Static simulation results.

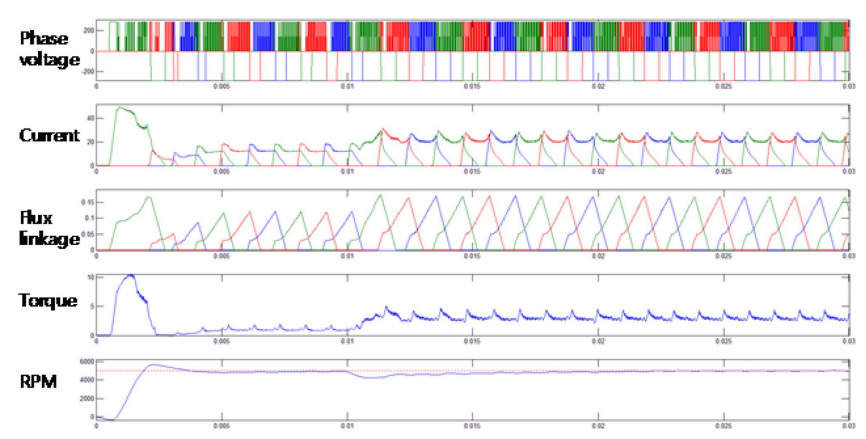

Fig. 12. (Color online) Dynamic simulation results.

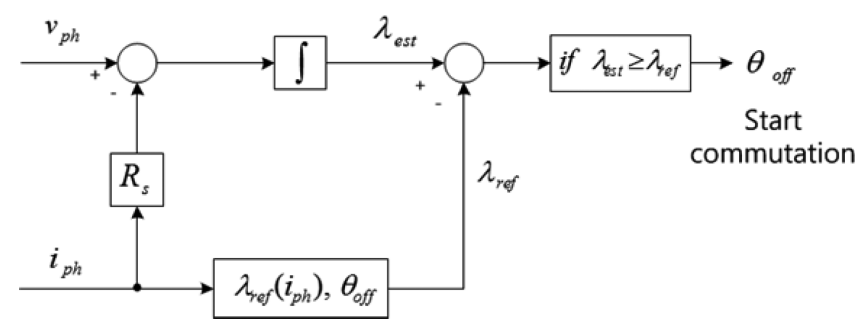

Fig. 13. Determination of turn-off angle.

time is calculated as follows.

$$
T_{o n}[n]=T_{o f f}[n-1]=\frac{\Delta T[n-1]}{\Delta \theta} \cdot\left(\Delta \theta+\theta_{c o m}-\theta_{a d v}\right)[s]
$$

where, $T_{o n}(\mathrm{n})$ is the turn-on time for current cycle(n), $T_{\text {off }}(\mathrm{n}-1)$ is the turn-off time for the previous cycle(n-1), and $\Delta T(\mathrm{n}-1)$ is the time interval between the two adjacent turn-off angles for the previous cycle(n-1).

In this paper, a conventional flux-based sensorless control method was implemented. The operation at high

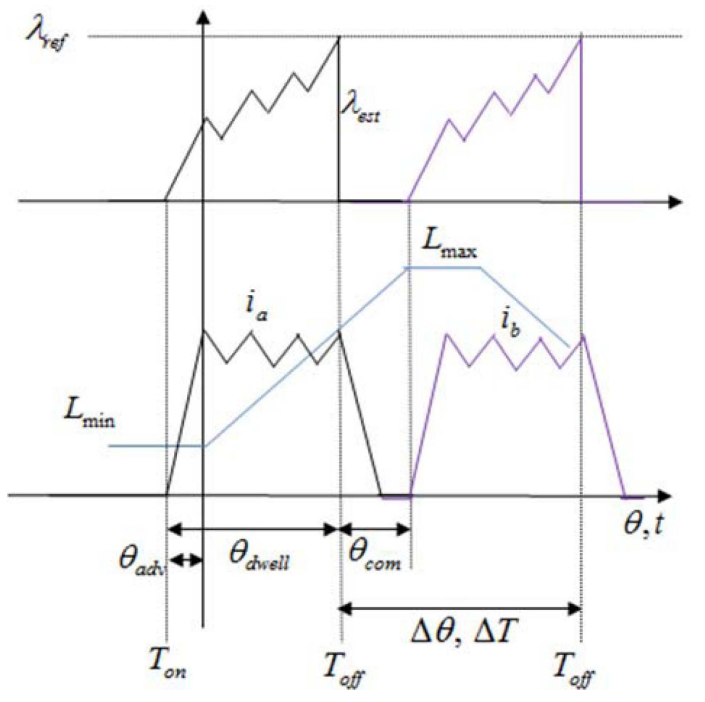

Fig. 14. (Color online) Relationship between inductance and rotor angular position.

speed was good, but the self-starting and low speed operation were not stable, and further $\mathrm{R} \& \mathrm{D}$ work is in progress.

\section{Experimental Results}

The prototype $3.5 \mathrm{~kW}$ SRM drive was constructed to run the scroll compressor for experimental tests. A block diagram of the experimental setup for load is depicted in Fig. 15. A 32bit floating-point DSP controller, TMS320F2808 was employed to implement the drive control algorithm.

The system efficiency and torque were measured, and are plotted in Fig. 16. The system efficiency has turned out to be somewhat lower than expected, because of manufacturing defects in the lamination and windings.

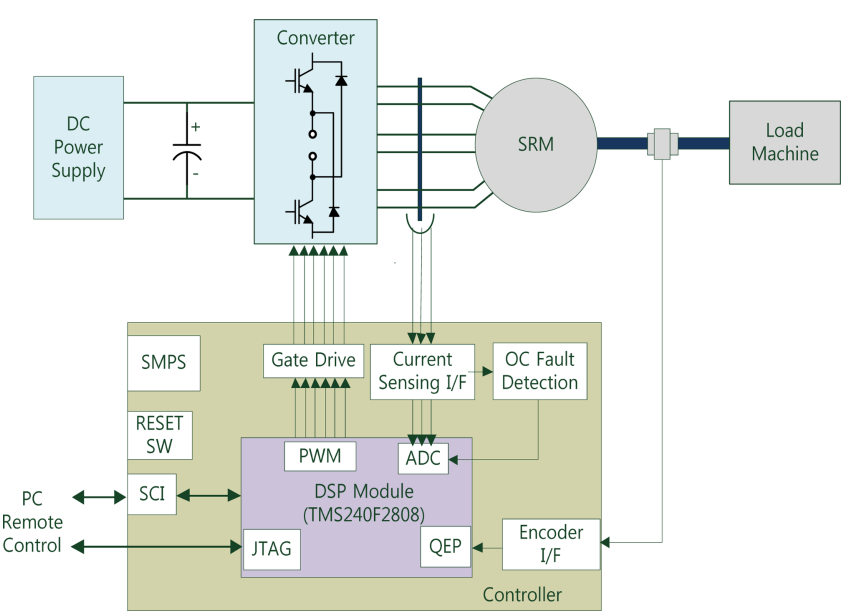

Fig. 15. (Color online) Block diagram of the experimental SRM drive system. 


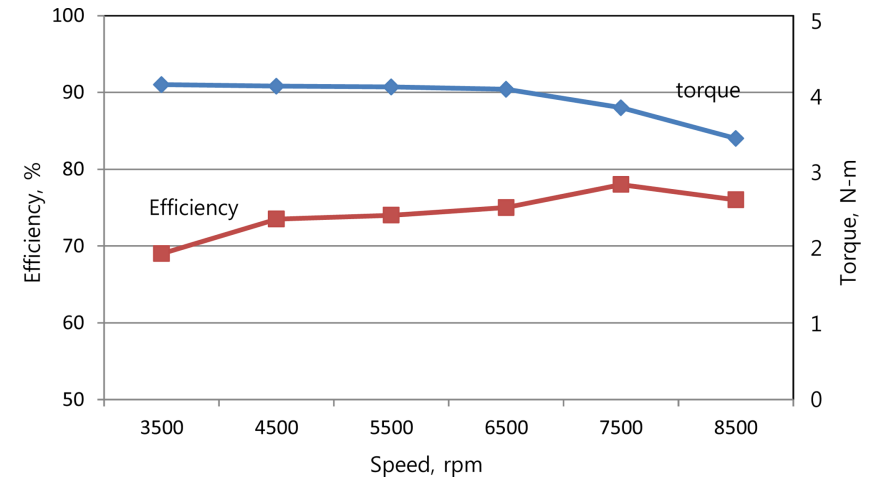

Fig. 16. (Color online) Measured system efficiency and torque over different operating speeds.

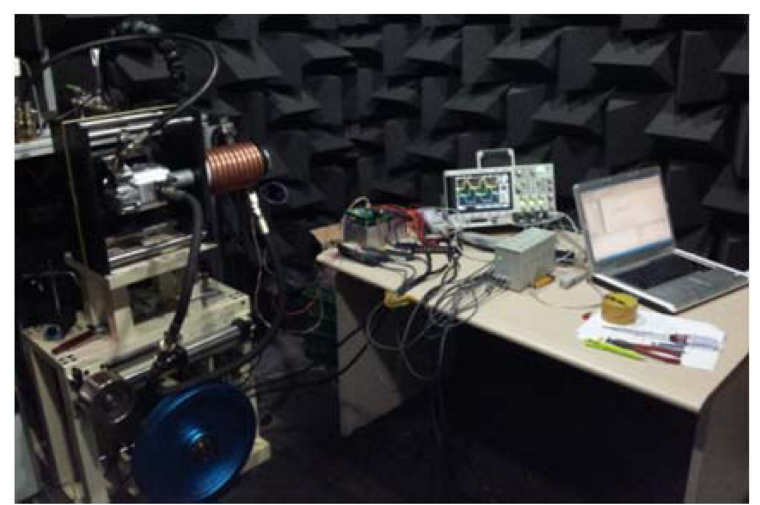

Fig. 17. (Color online) Experimental setup for load test of the SRM drive coupled with the compressor, inside a sound proof chamber.

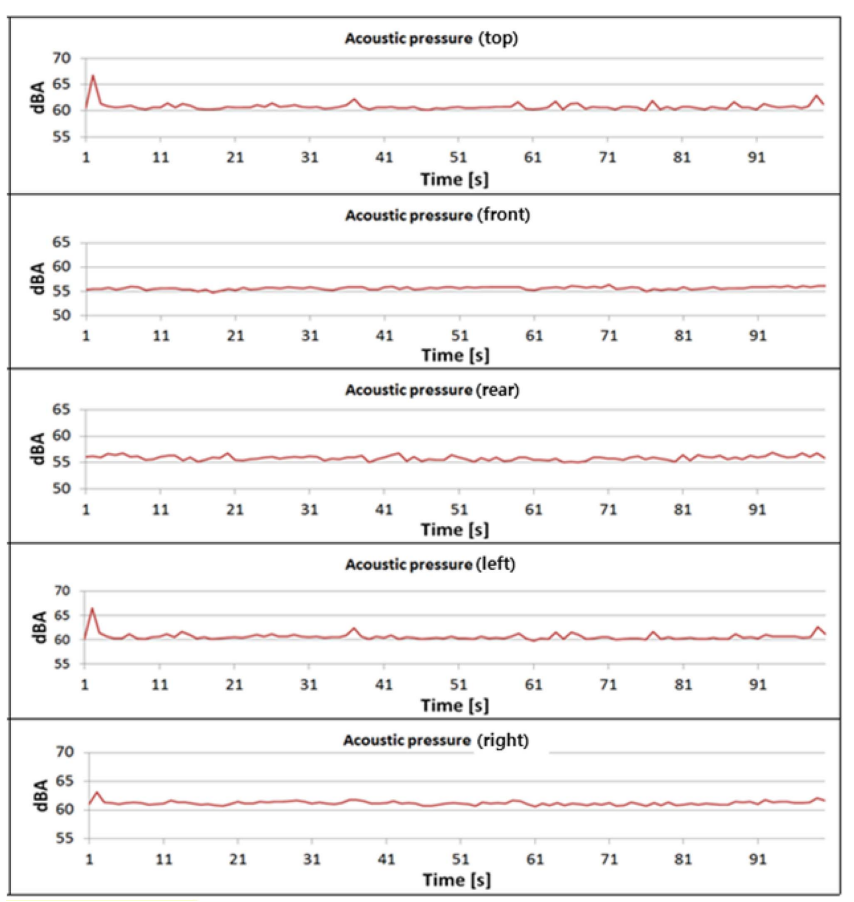

Fig. 18. (Color online) Acoustic noise measurement: instantaneous sound pressure level measured at five different points.
Table 3. Acoustic noise measurement: peak and average SPL measured at five different points

\begin{tabular}{cccccc}
\hline \hline SPL & Top & Front & Rear & Left & Right \\
\hline Peak (dBA) & 65.9 & 55.9 & 56.4 & 65.8 & 62.4 \\
Average (dBA) & 60.8 & 55.6 & 55.8 & 60.6 & 61.2 \\
\hline
\end{tabular}

Improved prototypes are undergoing development, and their results will be published in future literature.

Acoustic noise is one of the major drawbacks of the SRM. To investigate the acoustic noise emitted by the constructed prototype SRM drive, the whole drive setup was placed inside a soundproof chamber, and the sound pressure levels (SPLs) at four different points (top, front, rear, left, right) about $1 \mathrm{~m}$ away from the center of the motor weremeasured, as shown in Fig. 17. Fig. 18 and Table 3 show the results of the acoustic noise measurement. The test proved the prototype SRM drive satisfied the quantitative SPL specification of 70 [dB]. However, the unique sound of SRM commutation is still less favorable, compared to that of permanent magnet machines. The acoustic noise at single-pulse mode above the base speed is a bit higher than the PWM chopping mode, but this can be improved by utilizing a multi-stage commutation method at the end of commutation.

\section{Conclusion}

This paper discusses the development of a prototype electric compressor targeting EV/HEV applications, with a focus on the motor and its controller design. A threephase switched reluctance motor with asymmetric bridge converter was employed as an electric drive system to an AC compressor. A compact scroll compressor was also designed, in term of maximum cooling capacity, and mechanical durability. Two different types of machine configurations were considered, in terms of efficiency and torque ripple, and hence acoustic noise. Simulation based on analytic modeling of the machine integrated with the converter and closed-loop controller was performed, to validate both the static and dynamic performance of the drive system. Experimental tests, in terms of system efficiency and torque production, as well as acoustic noise emission, were also carried out, to verify the feasibility of the prototype drive system. The system efficiency turns out to be somewhat low, compared to the permanent magnet motor drives in commercially mass-produced electric compressors. However, their robustness and capability at high temperature and high speed operation still make SRMs beneficial to automotive applications. Hence, successful implementation of sensorless control plus improved motor efficiency would be the key to make SRMs a viable 
alternative to permanent magnet motors.

\section{Acknowledgments}

The research was supported by Wonkwang University in 2013.

\section{References}

[1] M. Naidu, T. W. Hehl, S. Gopalakrishnan, and L. Wurth, SAE Technical Paper Series, 2005-01-1318 (2008).

[2] G.-J. Su and J. S. Hsu, Conf. Proc. APEC 719 (2005).

[3] Delphi, Air Conditioning Compressors,delphi.com/pdf/ contact/brochures/Delphi_Compressors.pdf

[4] R. Krishnan, Switched Reluctance Motor Drives, CRC Press (2003).

[5] Trend in Electric Vehicle Market, KETI (2011).
[6] K. Jung, S. Cho, K. Cho, and C. Park, KSAE Conference Proc. 2160 (2011).

[7] T. J. E. Miller, Switched Reluctance Motors and Their Control, Magna Physics Publishing and Clarendon Press (1993).

[8] R. Krishnan, SWITCHED RELUCTANCE MOTOR DRIVE, Modeling, Simulation, Analysis, Design, and Applications (2001).

[9] V. Radun, IEEE Trans. Ind. Appl. 31, 1079 (1995).

[10] H. Hotta, Refrigeration 83, 964 (2008).

[11] J. P. Lyons, S. R. MacMinn, and M. A. Preston, Proc. IEEE-IAS'91 (1991).

[12] R. Visinka, 3-Phase SR Sensorless Motor Control using DSP56F80x, Motorola (2002).

[13] G. Gallegos-Lopez, P. C. Kjaer, and T. J. E. Miller, IEEE Trans. Ind. Appl. 34, 832 (1998). 